\title{
FINDRISC questionnaire as a potential screening strategy for gestational diabetes mellitus
}

\author{
Elif Meseci ${ }^{1 *}$, Yasar Ozlem Mericliler ${ }^{2}$, Ayse Gulcin Demirdoven ${ }^{3}$, Erdogan Aslan ${ }^{4}$, Semra Kayatas Eser ${ }^{5}$, Yasemin Kanek ${ }^{6}$, Mustafa Serteser ${ }^{7}$, \\ and Ali Murat Yayla ${ }^{8}$ \\ ${ }^{1}$ Obstetrics and Gynecology Department, Acıbadem Kozyatag1 Hospital, Istanbul, Turkey \\ ${ }^{2}$ Internal Medicine, Endocrinology and Metabolism Clinic, Acıbadem University Medical School , Acibadem Kozyatag1 Hospital, Istanbul, Turkey \\ ${ }^{3}$ Obstetrics and Gynecology Department, Fatih University Medical School, Istanbul, Turkey \\ ${ }^{4}$ Obstetrics and Gynecology Department, Yeni Karaman Mah, Bursa, Turkey \\ ${ }^{5}$ Obstetrics and Gynecology Department, Zeynep Kamil Education and Training Hospital, Istanbul, Turkey \\ ${ }^{6}$ Acıbadem Kozyatag1 Hospital, Istanbul, Turkey \\ ${ }^{7}$ Department of Medical Biochemistry, Acibadem Univesity, School of Medicine, Acibadem Labmed Clinical Laboratories, Istanbul, Turkey \\ ${ }^{8}$ Department of Perinatology, Acibadem Kozyatag1 Hospital, Istanbul, Turkey
}

\begin{abstract}
Objective: We aimed to determine the predictive value of FINDRISC score as a screening method for gestational diabetes mellitus (GDM).

Methods: A prospective, cross - sectional study was carried out with a total 111 pregnant women. At the first antenatal visit, FINDRISC questionnaire was filled out by one doctor. A $50 \mathrm{~g}$ oral glucose challenge test (GCT) was performed between the 24 - 28 th week of gestation. If the test exceeded the threshold value, a $3 \mathrm{~h} 100$ $\mathrm{g}$ oral glucose tolerance test (OGTT) was performed to confirm the diagnosis of GDM.

Results: 44 (39.6\%) of 111 patients GCT were positive. 17 patients (16.2\%) were newly diagnosed with GDM. The FINDRISC scores of the GDM (+) patients were found to be significantly higher than that of GDM (-) group with a cutoff value of >9. At this cutoff point the sensitivity, specifity, positive predictive value, negative predictive value, and + likelihood ratio were $52.94,79.79,32.1,90.4$, and 2.62 , respectively. The area under the ROC curve in the detection of GDM was $0.708 \pm 0.07$.
\end{abstract}

Conclusion: FINDRISC score may serve as an easy, non - invasive and cost - saving initial assessment tool for screening of GDM.

\section{Introduction}

Gestational diabetes mellitus (GDM) defined as glucose intolerance with onset or first recognition during pregnancy, occurs in $2-5 \%$ of all pregnancies [1]. It is associated with increased rates of adverse pregnancy outcomes, such as macrosomia, neonatal jaundice, neonatal hypoglycemia, and birth - related trauma. In addition, women with GDM are at higher risk for the development of type 2 diabetes mellitus (T2D) later in life [2]. Trials show that treatment of GDM by dietary restrictions and insulin therapy, if required, reduces the rate of perinatal complications [2]. Hence, identification and treatment of women with GDM is universally regarded as one of the primary goals of obstetric health care givers, as prompted by many professional authorities including World Health Organization (WHO), American Congress of Obstetricians and Gynecologists (ACOG), Royal College of Obstetricians and Gynaecologists (RCOG), American Diabetes Association (ADA) and similars [3-6].

GDM and T2D has many common pathophysiologic abnormalities like insulin resistance, hyperinsulinemia, and beta-cell hypofunction [1]. The distinctive features of T2D such as older age, higher body mass index (BMI), and family history of diabetes are also proved to be independent risk factors for the development of GDM $[7,8]$. Genetically it has been shown that T2D risk alleles are more frequent among women with a history of GDM [9]. These data raises the argument that GDM may be a phase of the syndrome of insulin resistance [1].

Many studies proved that if high risk individuals could be detected in the prediabetic state, preventive attempts like life style modification and the use of insulin sensitizing drugs such as metformine could prevent or delay the development of T2D [6]. This urge for the early detection of the high risk individuals resulted in a search for the development of a simple, practical and informative scoring system for screening the population. FINDRISC score is a questionnaire designed to screen the population for increased T2D risk and several studies showed a correlation of a high FINDRISC score and the diagnosis of any degree of glucose metabolism disorder [10]. However, there have been no publications found on the use of the Findrisc for screening of

Correspondence to: Elif MESECI, Medical Doctor, Obstetrics and Gynecology Department, Acıbadem Kozyatagı Hospital, Inonu Cd. Okur S. No:20 Kozyatag1 34742 Istanbul, Turkey, Tel: +90 21657143 30; Fax: + 9021657140 00; E-mail: elfmsc@yahoo.com

Key words: findrisc score, gestational diabetes mellitus, screening

Received: January 19, 2016; Accepted: February 16, 2016; Published: February 19,2016 


\section{GDM during pregnancy in particular.}

Our aim in this study was to investigate whether FINDRISC questionnaire could be used as a screening method to detect women with increased risk of having GDM.

\section{Materials and method}

In this prospective, cross-sectional study 111 women followed during their pregnancy at the outpatient obstetric department of Kozyatag1 Acıbadem Hospital, Istanbul, Turkey, between 2011 - 2013 were invited to participate. Individuals were eligible if they had no prior chronic medical illness, not taking glucocorticoids. Women with a history of preexisting diabetes, who delivered before 28 weeks of gestation and multifetal gestations were excluded from the study. All participants were informed about the aim of the study and gave written informed consent to attend. This study was approved by the ethics committee of Acibadem University of Medical School.

Patients that came to the first antenatal follow up before the $4^{\text {th }}$ gestational week, whose $\beta$ - human chorionic gonadotrophin ( $\beta$-hcg) tests were positive but gestational sac were not observed by ultrasound, were included to our study. Heights, waist circumferences, weights of the patients were measured by trained personnel. BMI was calculated as weight $(\mathrm{kg}) /\left[(\text { height }(\mathrm{m})]^{2}\right.$. Obstetric history, history of previous pregnancies, family history of diabetes, age, smoking habits were noted. 111 women who accepted to participate had replied the questions of the FINDRISC questionnaire at the same visit by one doctor.

The FINDRISC is calculated based on a simple questionnaire with 8 questions, including age (years), BMI $\left(\mathrm{kg} / \mathrm{m}^{2}\right)$, waist circumference (WC: $\mathrm{cm}$ ), history of antihypertensive drug treatment, history of high blood glucose, family history of diabetes, daily consumption of fruits, berries, or vegetables (consume every day vs. not), and daily physical activity (having at least 30 minutes of physical activity during work or at leisure time $v s$. not). It is shown in Tables 1 and 2 [10]. The answer of

Table 1. Type 2 diabetes risk test (FINDRISC questionnaire) [10].

\begin{tabular}{|l|c|c|}
\hline Finnish diabetes risk score & & Point (s) \\
\hline Age & $<35$ & 0 \\
& $35-44$ & 1 \\
& $45-54$ & 2 \\
& $55-64$ & 3 \\
\hline Family History of T2D & $>64$ & 0 \\
& None & 5 \\
& Parents, siblings, children & 3 \\
grandparents, aunt, uncle, & (highest score is 5) \\
\hline Waist circumference (cm) & cousin & \\
& & 3 \\
& Female/Male & 4 \\
\hline Exercise & $<80 /<94$ & 0 \\
(at least 30 min/day) & $>88 / 94-102$ & 2 \\
\hline Diet: daily vegetables, fruit and fiber & $>88 />102$ & 0 \\
\hline consumption & Yes & 1 \\
\hline Hypertension & No & 0 \\
\hline History of high blood glucose & Yes & 2 \\
\hline Body mass index $\left(\mathrm{kg} / \mathrm{m}^{2}\right.$ ) & No & 0 \\
\hline & & 5 \\
\hline
\end{tabular}

Table 2. Evaluation of FINDRISC (diabetes risk score) [10].

\begin{tabular}{|c|c|c|}
\hline Total scores (points) & Risk rating & $\mathbf{1 0 - y e a r ~ r i s k ~}$ \\
\hline$<7$ & Low & $1 \%(1 / 100)$ \\
\hline $7-11$ & Mild & $4 \%(1 / 25)$ \\
\hline $12-14$ & Moderate & $16 \%(1 / 6)$ \\
\hline $15-20$ & High & $33 \%(1 / 3)$ \\
\hline$>20$ & Very high & $50 \%(1 / 2)$ \\
\hline
\end{tabular}

every question is assigned with different weighted scores according to the risk increase associated with the respective values in the regression model in the original cohort. The final score is the sum of thescores from 8 questions and ranges from 0 to 26 .

During monthly follow - up, weight gain at each trimester, laboratory tests including $50 \mathrm{~g}$ glucose challenge test (GCT) and if performed $100 \mathrm{~g} 3 \mathrm{~h}$ oral glucose tolerance test (OGTT), the follow - up method of any newly diagnosed GDM (diet and/or insulin), diabetes regulation parameters such as $\mathrm{HbAlc}$ and fructosamine, duration of pregnancy in days, birth weight of the neonate in grams, and Apgar score of the neonate were recorded.

For diagnosis of GDM, we used two-step approch according to ADA 2010 definitions [12]. A $50 \mathrm{~g}$ oral glucose challenge test was performed between the $24-28^{\text {th }}$ week of gestation. The test was performed irrespective of time of the day and of the last meal. Plasma glucose was measured $1 \mathrm{~h}$ after administration of a solution containing $50 \mathrm{~g}$ glucose. The predefined cutoff value for an abnormal test result was a $1 \mathrm{~h}$ plasma glucose value of $>140 \mathrm{mg} / \mathrm{dl}$ [12]. If $50 \mathrm{~g}$ oral glucose challenge test exceeded the predefined threshold value, a $3 \mathrm{~h} 100$ g OGTT was performed within one week to rule out or confirm the diagnosis of GDM. The OGTT was performed in the morning after 8 to $12 \mathrm{~h}$ overnight fast and 3 days of normal carbohydrate diet (150 $200 \mathrm{~g}$ /day). A positive OGTT was defined according to Carpenter and Coustan thresholds as two or more values that were abnormal: fasting $\geq 96 \mathrm{mg} / \mathrm{dl}, 1 \mathrm{~h} \geq 180 \mathrm{mg} / \mathrm{dl}, 2 \mathrm{~h} \geq 155 \mathrm{mg} / \mathrm{dl}, 3 \mathrm{~h} \geq 140 \mathrm{mg} / \mathrm{dl}[12,13]$.

HbAlc and fructosamine were measured in patients with confirmed GDM and fructosamine was repeated monthly as a marker for blood sugar regulation.

Glucose, fructosamine and HbAlc levels were analyzed in Cobas Integra 400 by using reagents from Roche Diagnostics.

Statistical calculations were performed with NCSS (Number Cruncher Statistical System) 2007 Statistical Software (Utah, USA) program for Windows. Besides standard descriptive statistical calculations (mean, standard deviation) unpaired t test was used in the comparison of two groups, and Chi square test and odds ratio was performed during the evaluation of qualitative data. The results were evaluated within a $95 \%$ confidence interval. Statistical significance level was established at $\mathrm{p}<0.05$.

To calculate the sensitivity, specificity, positive predictive value (PPV), negative predictive value (NPV) and likelihood ratio (LR) (+) for the FINDRISC score measurements at varying cut - off values, a conventional receiver operating characteristic curve was generated and the area under the curve (AUC) was calculated for FINDRISC scores.

\section{Results}

111 women were included to the study. 44 (39.6\%) of 111 patients oral glucose challenge test were positive. Based on oral glucose tolerance test, 17 patient (16.2\%) were newly diagnosed with gestational diabetes 
mellitus, 26 patients $(23.4 \%)$ had impaired glucose tolerance .The descriptive properties of the participants were shown in Table 3.

Age, number of pregnancies, BMI, own birth weight of mothers, and the level of education were statistically similar both in GDM (+) and (-) groups.

Smoking history was statistically higher in the GDM (+) group $(\mathrm{n}=4,23 \%, \mathrm{p}=0.03)$. Cessation of smoking was comparable between groups.

Family history of DM in any relative showed 2.5 fold increased risk in GDM (+) group whereas T2D history of the mother, father, siblings, and second degree relative showed a 2.37, 2.7, 3, and 2.5 fold increase for the risk of GDM, respectively. The odds ratios (OR) were shown in Table 4.

Total weight gain in the GDM $(+)$ group during $1^{\text {st }}$ trimester, and $2^{\text {nd }}$ trimester and entire pregnancy were statistically higher than that of GDM (-) group ( $\mathrm{p}=0.0001, \mathrm{p}=0.001, \mathrm{p}=0.0001$, respectively). There was no significant difference for the weight gain during the $3^{\text {rd }}$ trimester among the groups $(\mathrm{p}=0.586)$. Weight characteristics of the participants were shown in Table 3. Pregnancy duration was similar in both groups as well as the birth weight of the neonates $(\mathrm{p}=0.346$ and $\mathrm{p}=0.156$, respectively; Table 3 ).

Table 3. Characteristics of the study population.

\begin{tabular}{|l|l|l|l|}
\hline & GDM (-) & GDM (+) & p \\
\hline $\mathrm{n}$ & 94 & 17 & \\
\hline Age & $32.24 \pm 4.22$ & $33.41 \pm 3.55$ & 0.286 \\
\hline BMI $\left(\mathrm{kg} / \mathrm{m}^{2}\right)$ & $22.62 \pm 3.71$ & $24.41 \pm 3.73$ & 0.069 \\
\hline Smoking & & & \\
No & $\mathrm{n}=6771.28 \%$ & $\mathrm{n}=847.06 \%$ & \\
Yes & $\mathrm{n}=77.45 \%$ & $\mathrm{n}=423.53 \%$ & $\mathbf{0 . 0 3}$ \\
Quit & $\mathrm{n}=2021.28 \%$ & $\mathrm{n}=529.41 \%$ & 0.308 \\
\hline $\begin{array}{l}\text { Educational attainment } \\
\text { Primary school }\end{array}$ & $\mathrm{n}=11.06 \%$ & $\mathrm{n}=15.88 \%$ & \\
\hline $\begin{array}{l}\text { High school } \\
\text { College }\end{array}$ & $\mathrm{n}=99.57 \%$ & $\mathrm{n}=317.65 \%$ & \\
\hline $\begin{array}{l}\text { Parity } \\
1\end{array}$ & $\mathrm{n}=8489.36 \%$ & $\mathrm{n}=1376.65 \%$ & 0.091 \\
\hline $\begin{array}{l}2 \\
3\end{array}$ & $\mathrm{n}=7579.79 \%$ & $\mathrm{n}=1694.12 \%$ & \\
Duration of pregnancy (weeks) & $\mathrm{n}=31.19 \%$ & $\mathrm{n}=15.88 \%$ & 0.035 \\
\hline Birth weight of the infant (gr) & $38.72 \pm 1.26$ & $38.41 \pm 1.06$ & 0.346 \\
\hline $\begin{array}{l}\text { Rate of weight gain (kg) } \\
1^{\text {st trimester }}\end{array}$ & $3434.19 \pm$ & $3282.71 \pm 293.49$ & 0.156 \\
$2^{\text {nd trimester }}$ & $1.06 \pm 1.46$ & $2.82 \pm 0.93$ & 0.0001 \\
$3^{\text {rd trimester }}$ & $5.81 \pm 1.68$ & $7.03 \pm 2.07$ & 0.001 \\
\hline Total weight gain & $6.72 \pm 2.31$ & $7.04 \pm 2.03$ & 0.586 \\
\hline
\end{tabular}

Table 4. Odds ratios and $95 \%$ confidence intervals for GDM associated with family history of T2D. OR: odds ratio; CI: confidence interval; Data are $\mathrm{n}(\%)$ or odds ratio $(95 \% \mathrm{CI})$.

\begin{tabular}{|l|l|l|l|l|}
\hline $\begin{array}{l}\text { Family history of } \\
\text { T2D }\end{array}$ & GDM ( - ) & GDM (+) & p & OR (95\% CI) \\
\hline None & $\mathrm{n}=4143.62 \%$ & $\mathrm{n}=423.53 \%$ & & \\
\hline Mother & $\mathrm{n}=1313.83 \%$ & $\mathrm{n}=317.65 \%$ & 0.365 & $\mathbf{2 . 3 7}(0.47-11.98)$ \\
\hline Father & $\mathrm{n}=1515.96 \%$ & $\mathrm{n}=423.53 \%$ & 0.223 & $\mathbf{2 . 7}(0.61-12.4)$ \\
\hline Sibling & $\mathrm{n}=11.06 \%$ & $\mathrm{n}=00.00 \%$ & 0.999 & $\mathbf{3}(0.11-87.27)$ \\
\hline Second degree relative & $\mathrm{n}=2425.53 \%$ & $\mathrm{n}=635.29 \%$ & 0.185 & $\mathbf{2 . 5}(0.66-10)$ \\
\hline $\begin{array}{l}\text { Any family history } \\
\text { of T2D } \\
\begin{array}{l}\text { None } \\
(+)\end{array}\end{array}$ & $\begin{array}{l}\mathrm{n}=4143.62 \% \\
\mathrm{n}=5356.38 \%\end{array}$ & $\begin{array}{l}\mathrm{n}=423.53 \% \\
\mathrm{n}=1376.47 \%\end{array}$ & 0.021 & $\mathbf{2 . 5}(0.76-8.29)$ \\
\hline
\end{tabular}

Table 4. Odds ratios and 95\% confidence intervals for GDM associated with family history of T2D. OR: odds ratio; CI: confidence interval; Data are $\mathrm{n}(\%)$ or odds ratio $(95 \% \mathrm{CI})$.

\begin{tabular}{|l|l|l|l|}
\hline & $\begin{array}{l}\text { GDM ( - ) } \\
\mathbf{n = 9 4}\end{array}$ & $\begin{array}{l}\text { GDM (+) } \\
\mathbf{n = 1 7}\end{array}$ & \\
\hline FINDRISC & $6.13 \pm 3.6$ & $9 \pm 3.64$ & $\mathbf{p = 0 . 0 0 3}$ \\
\hline & & FINDRISC $\leq \mathbf{2}$ Risk & \\
\hline $\begin{array}{l}\text { Area under the ROC } \\
\text { curve (AUC) }\end{array}$ & & $\mathbf{0 . 7 0 8} \pm \mathbf{0 . 0 7}$ & \\
\hline
\end{tabular}

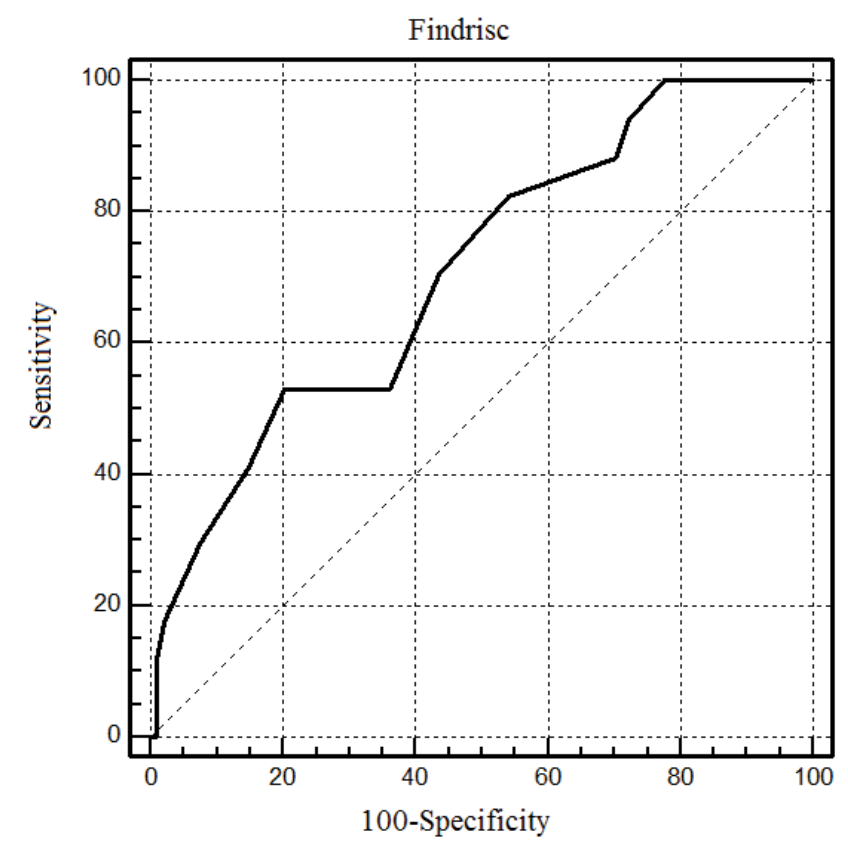

Figure 1. Area under receive-operating characteristic curve (AUC) of FINDRISC score values to predict GDM.

FINDRISC score of the GDM $(+)(9 \pm 3.64)$ group was significantly higher than the GDM (-) $(6.13 \pm 3.6)$ group $(\mathrm{p}=0.003)$. The area under the ROC curve with less than 2 risk factors in the detection of GDM was $0.708 \pm 0.07$, as shown in Table 5 .

The cutoff value for the FINDRISC score was $>9$ and at this cutoff point the sensitivity, specifity, positive predictive value, negative predictive value, and + LR were 52.94, 79.79, 32.1, 90.4, and 2.62, respectively, as shown in Table 6 . Criterion values and coordinates of the ROC curve were shown in Figure 1.

\section{Discussion}

The first important observation resulting from our study is the significant difference of the FINDRISC score among the GDM (+) and (-) groups. The FINDRISC scores of the GDM (+) patients were found to be significantly higher than that of GDM (-) group with a cutoff value of $>9$. FINDRISC score $>9$ had a sensitivity, specifity, positive predictive value, negative predictive value, and + LR were $52.94,79.79,32.1,90.4$, and 2.62 , respectively. So a pregnant with $>$ 9 FINDRISC has 2.62 times more risk to be GDM than a pregnant with $<9$. Although there was sufficient data about the predictive value of the FINDRISC questionnaire as a potential screening strategy for T2D in healthy population [11], so far we did not meet any published data about FINDRISC questionnaire used for the evaluation of GDM during pregnancy. Crowe et al. compared FINDRISC score with $75 \mathrm{~g}$ OGTT in a population with a history of GDM to predict prediabetes/ 
Table 6. Treshold values for FINDRISC score showing sensitivity, specificity, PPV, NPV along with $\mathrm{LR}+/ \mathrm{LR}$ - tests. PPV/NPV: positive/negative predictive value, LR+/LR - : likelihood ratio of positive/negative tests.

\begin{tabular}{|c|c|c|c|c|c|c|}
\hline Criterion & Sensitivity & Specificity & PPV & NPV & + LR & - LR \\
\hline$>0$ & 100.00 & 6.38 & 16.2 & 100.0 & 1.07 & 0.00 \\
\hline$>1$ & 100.00 & 7.45 & 16.3 & 100.0 & 1.08 & 0.00 \\
\hline$>2$ & 100.00 & 22.34 & 18.9 & 100.0 & 1.29 & 0.00 \\
\hline$>3$ & 94.12 & 27.66 & 19.0 & 96.3 & 1.30 & 0.21 \\
\hline$>4$ & 88.24 & 29.79 & 18.5 & 93.3 & 1.26 & 0.39 \\
\hline$>5$ & 82.35 & 45.74 & 21.5 & 93.5 & 1.52 & 0.39 \\
\hline$>6$ & 70.59 & 56.38 & 22.6 & 91.4 & 1.62 & 0.52 \\
\hline$>7$ & 52.94 & 63.83 & 20.9 & 88.2 & 1.46 & 0.74 \\
\hline$>8$ & 52.94 & 75.53 & 28.1 & 89.9 & 2.16 & 0.62 \\
\hline$>\mathbf{9 *}$ & $\mathbf{5 2 . 9 4}$ & $\mathbf{7 9 . 7 9}$ & $\mathbf{3 2 . 1}$ & $\mathbf{9 0 . 4}$ & $\mathbf{2 . 6 2}$ & $\mathbf{0 . 5 9}$ \\
\hline$>10$ & 41.18 & 85.11 & 33.3 & 88.9 & 2.76 & 0.69 \\
\hline$>11$ & 29.41 & 92.55 & 41.7 & 87.9 & 3.95 & 0.76 \\
\hline$>12$ & 17.65 & 97.87 & 60.0 & 86.8 & 8.29 & 0.84 \\
\hline$>13$ & 11.76 & 98.94 & 66.7 & 86.1 & 11.06 & 0.89 \\
\hline$>14$ & 5.88 & 98.94 & 50.0 & 85.3 & 5.53 & 0.95 \\
\hline$>15$ & 0.00 & 98.94 & 0.0 & 84.5 & 0.00 & 1.01 \\
\hline$>16$ & 0.00 & 100.00 & & 84.7 & & 1.00 \\
\hline
\end{tabular}

diabetes and concluded it to be a convenient screening method helping to determine which patients may need more frequent screening post GDM [12].

Our findings about the risk factors for GDM were largely in concordance with the literature with some exceptions. Although our GDM (+) patients were slightly older, there was no significant difference among the groups. Age is classically used in risk scores for GDM and it is one of the questions in FINDRISC questionnaire. Cosson et al. reported that women $>35$ years old compared with those $<25$ had a twofold increased risk of GDM [13]. Similarly BMI was insignificantly higher in the GDM (+) group compared to the GDM (-) group. Weight is also a widely accepted risk factor for GDM and a part of FINDRISC questionnaire. A recent meta-analysis showed that for each increasing kilogram per meter squared of BMI, the prevalence of GDM rose by $0.92 \%$ [14]. The disconcordance of our results to the current literature on age and BMI might be because of our small sample size. However, ethnic differences among the study populations, different BMI cut - off values used to define obesity in different studies, and the strict diet of our overweight/obese patients to control weight gain during pregnancy may be other factors. But our finding that total gestational weight gain as well as the $1^{\text {st }}$ and $2^{\text {nd }}$ trimester weight gain were significantly higher in the GDM $(+)$ group was consistently supported by the literature $[8,15]$.

Family history of diabetes has been reported to increase the risk for the development of GDM by 1.6 - 3.0 fold in different series [16,17]. In our patient group family history of T2D in any relative showed 2.5 fold increased risk. Although some studies emphesized different risk ratios for paternal or maternal T2D history [18], in our study group T2D history of the mother, father, siblings, and second degree relatives showed a comparable increase at the risk of $\operatorname{GDM}(2.37,2.7,3$, and 2.5 fold increase, consecutively).

Historically, HbAlc measurements and fructosamine levels did not adequately discriminate women with normal pregnancy from those with GDM, even though HbAlc levels were proved to decline in normal pregnancy [19]. In this aspect, our findings were also consistent with literature and monthly repeated fructosamine measurements in
GDM patients were comparable with the baseline values at the time of the GDM diagnosis.

Our study has some limitations. First, our sample number was low. Another limitation is the possibility of misclassification on diagnosis of GDM because not all participants had OGTT for definitive diagnosis. Although GCT was used to define GDM (+) and (-) cases, its use may impact our sensitivity, specificity and other satistical results. We do not have evidence that FINDRISC score $>9$ is associated with poorer pregnancy outcome, or that treatment from early pregnancy prevent complications, because we had small sample size and had not any perinatal comlications. Thus, it is an important area of further research. The strength of our study is that selection and information bias were unlikely because of the prospective design.

As for the neonatal outcomes, we did not find any difference between groups for macrosomia, prematurity, or any other neonatal complications. This may be due to the fact that the blood glucose levels of all of our diabetic patients remained below the target values.

The traditional diabetes screening methods, including the fasting plasma glucose (FPG), OGTT or HbAlc test, are invasive and expensive. A simple, non -invasive, cost effective and sensitive screening tool is needed in the primary care setting, especially in lowincome countries. We suggest that using FINDRISC score at the first antenatal visit as a preliminary screening method followed with more invasive and accurate diagnosis in primary care can be a cost - effective and practical method.

Overall, we assume that risk factors proposed in FINDRISC questionnaire successfully predicted GDM. However, prospective studies conducted over larger populations should clarify the clinical relevance of this result. In two large series of Cosson and Jensen, despite a detailed screening of the risk factors the diagnosed number of GDM patients were very low and Cosson emphasized that $34.7 \%$ of women with GDM would have been missed without universal screening [13,17]. But both of the studies showed that the prevalence of GDM was particularly high when the number of risk factors was greater than three. Since FINDRISC questionnaire analyses eight different risk factors, the cutoff $>9$ was assumed to be equivalent to three or more positive scores.

In conclusion, women with a history of GDM are considered as high-risk individuals for the development of T2D in later life, and GDM is proved to share many common features and risk factors with T2D such as insulin resistance, obesity, and family history of T2D. The early detection and treatment is warranted not only a significant burden for the patients themselves but also for the health care system and the national economy. FINDRISC score may serve as an easy, non - invasive and cost saving initial assessment tool to diagnose women with these features at the beginning of pregnancy leading to take early precautions such as diet and exercise and may lead to lower perinatal complications.

\section{Acknowledgements}

We thank all the participants for attending in this study.

\section{Conflict of interest statement}

The authors declare that they have no conflicts of interest.

\section{References}

1. Clark MC, Qui C, Amerman B, Porter B, Fineberg N, et al. (1997) Gestational 
Diabetes: Should it be added to the syndrome of insulin resistance? Diab Care 20: 867 - 871. [Crossref]

2. Van Leeuwen M, Zweers EJK, Opmeer B, Van Ballegooie E, Ter Brugge HG, et al. (2007) Comparison of accuracy measures of two screening tests for gestational diabetes mellitus. Diab Care 30: 2779-2784. [Crossref]

3. World Health Organization (WHO) 2013. Diagnostic Criteria and Classification Of Hyperglycaemia Firs Detected in Pregnancy. WHO 2013.WHO / NMH / MND13.2

4. American College of Obstetricians and Gynecologist (ACOG). Gestational Diabetes Mellitus.Washington (DC): American College of Obstetricians and Gynecologist (ACOG); 213 Aug.11.p. (ACOG practice bulletin; no137)

5. Royal College of Obstetricians and Gynaecologists (RCOG). Diagnosis and Treatment of Gestational Diabetes.Scientific Impact Paper No.23, Jan.2011.

6. American Diabetes Association (ADA). Standards of Medical Care in Diabetes - 2014. Diabetes Care Volume 37, January 2014.

7. Cypryk K, Szymczak W, Czupryniak L, Sobczak M, Lewiski A (2008) Gestationa diabetes mellitus-an analysis of risk factors. Endocrynol Pol 59: 393 -397. [Crossref]

8. Heude B, Thiebaugeorges O, Goua V, Forhan A, Kaminski M, et al. (2012) Prepregnancy body mass index and weight gain during pregnancy: relations with gestational diabetes and hypertension, and birth outcomes. Matern Child Health $J$ 16: 355 - 363. [Crossref]

9. Lauenborg J, Grarup N, Damm P, Borch-Johnsen K, Jorgensen T, et al. (2009) Common type 2 diabetes risk gene variants associate with gestational diabetes. J Clin Endocrinol Metab 94: 145-150. [Crossref]

10. Lindstrom J, Toumilehto J (2003) The diabetes risk score: a practical tool to predict type 2 diabetes risk. Diab Care 26: 725-731. [Crossref]

11. Lindström J, Peltonen M, Eriksson JG, Aunola S, Hamalainen H, et al. (2008) Determinants for the effectiveness of lifestyle intervention in the Finnish Diabetes Prevention Study. Diab Care 31: 857-862. [Crossref]
12. American Diabetes Association (ADA). Standards of Medical Care in Diabetes - 2010 (2010) Diabetes Care 33: S62-S69. [Crossref]

13. Carpenter MW, Coustan DR (1982) Criteria for screening tests for gestational diabetes. Am J Obstet Gynecol 144: 768-773. [Crossref]

14. Makrilakis K, Liatis S, Grammatikou S, Zacharopoulou O, Tigas S, et al. (2007) Screening for diabetes and pre-diabetes using the FINDRISK questionnaire in a random Greek population: The Deplan type 2 diabetes prevention study. Diabetes 56: pA629.

15. Crowe C, Noctor E, Carmody LA, Wickham B, Avalos G, et al. (2012) Validation of a diabetes risk score in identifying patients at risk of progression to abnormal glucose tolerance post partum. BMC Proceedings 6: $\mathrm{O} 36$

6. Cosson E, Benbara A, Pharisien I, Nguyen MT, Revaux A, et al (2013) Diagnostic and prognostic performances over 9 years of a selective screening strategy for gestational diabetes mellitus in a cohort of 18,775 subjects. Diab Care 36: 598-603. [Crossref]

17. Torloni MR, Betran AP, Horta BL, Nakamura MU, Atallah AN, et al. (2010) Prepregnancy BMI and the risk of gestational diabetes:a systematic review of the literature with meta-analysis. Obes Rev 10: 194-203. [Crossref]

18. Cheng YW, Chang JH, Kurbisch-Block I, Inturrisi M, Shafer S, et al. (2008) Gestational weight gain and gestational diabetes mellitus. Obstet Gynecol 112: 10151022. [Crossref]

19. Galtier F (2006) Definition, epidemiology, risk factors. Diabetes Metab 32: 140-146.

20. Jensen DM, Molsted-Pederson L, Beck-Nielsen H, Westergaard JG, Ovesen P, et al. (2003) Screening for gestational diabetes mellitus by a model based on risk predictors: a prospective study. Am J Obstet Gynecol 34: 719-728. [Crossref]

21. Tabak AG, Tamas G, Peterfalvi A, Bornyak Z, Madarasz E, et al. (2009) The effect of paternal and maternal history of diabetes mellitus on the development of gestational diabetes mellitus. J Endocrinol Invest 32: 606-610. [Crossref]

22. Nielsen LR, Ekbom P, Damm P, Glümer C, Frandsen MM, et al. (2004) HbA1c levels are significantly lower in early and late pregnancy. Diab Care 27: 1200-1201. [Crossref]

Copyright: $(02016$ Meseci E. This is an open-access article distributed under the terms of the Creative Commons Attribution License, which permits unrestricted use, distribution, and reproduction in any medium, provided the original author and source are credited. 